\title{
Randomized clinical trial comparing monolithic and veneered zirconia three-unit posterior fixed partial dentures in a complete digital flow: three-year follow-up
}

\author{
Paula Pontevedra $^{1} \cdot$ Carlos Lopez-Suarez $^{1} \cdot$ Veronica Rodriguez $^{1} \cdot$ Jesus Pelaez $^{1}{ }^{\circledR} \cdot$ Maria J. Suarez $^{1}$
}

Received: 5 August 2021 / Accepted: 3 February 2022 / Published online: 10 February 2022

(c) The Author(s), under exclusive licence to Springer-Verlag GmbH Germany, part of Springer Nature 2022

\begin{abstract}
Objectives To evaluate and to compare the clinical performance and survival rate of posterior monolithic and veneered zirconia fixed partial dentures (FPDs).

Material and methods Sixty 3-unit posterior FPDs were included in the study. The patients were randomly distributed into two groups $(n=30$ each) to receive either a monolithic (Zenostar T, Wieland Dental) or veneered zirconia (IPS e.max ZirCAD, Ivoclar Vivadent) FPD. Each patient received only 1 FPD. Tooth preparations were scanned (Trios 3, 3Shape), designed (Dental System 2016, 3 Shape), milled (Zenotec CAM 3.2, Wieland Dental), and cemented with a resin cement. Technical and biological outcomes and periodontal parameters were assessed. Data analysis was made using the Friedman and the Wilcoxon signed-rank tests with the Bonferroni correction and the Mann-Whitney $U$ test.

Results The survival rate at 3 years was 100\% for veneered and $90 \%$ for monolithic zirconia restorations. Three monolithic zirconia FPDs were lost because of biologic complications. The main complication in the veneered zirconia FPDs was the fracture of the veneering ceramic in 4 of the veneered zirconia FPDs. No fracture of the frameworks was observed in any of the groups. All restorations were assessed as satisfactory after 3 years. No differences in periodontal parameters were observed between the groups.

Conclusions The results of this study suggest that monolithic zirconia and complete digital flow could be a viable alternative to veneered zirconia in the posterior regions.

Clinical relevance The monolithic zirconia restorations with a digital workflow can be a viable alternative in posterior fixed partial dentures, with good periodontal outcomes.
\end{abstract}

Clinical trial registration number ClinicalTrials.gov (Identifier NCT 04,879,498).

Keywords Fixed partial dentures $\cdot$ Monolithic zirconia $\cdot$ Veneered zirconia $\cdot$ Clinical evaluation $\cdot$ Survival

\section{Introduction}

The esthetic demand of patients has increased leading to the search for alternatives to metal-ceramic (MC) restorations. This material is considered the gold standard for posterior fixed partial dentures (FPDs), showing survival rates of $93.8 \%$ at 5 years and $89.2 \%$ at 10 years of follow-up [1]. All new materials should provide results comparable to those

Jesus Pelaez

jpelaezr@ucm.es

1 Department of Conservative Dentistry and Buccofacial Prostheses, Faculty of Odontology, University Complutense of Madrid, Pza Ramon y Cajal s/n, Madrid, Spain obtained with MC restorations [1-8]. The introduction of new materials and fabrication methods offers different possibilities to remove the metal coping from MC restorations. When esthetics are a priority, ceramic restorations are the best option because their natural appearance [9]. However, currently, less scientific evidence available exists for ceramic compared to MC restoration [10-12].

Mechanical properties are an important factor to select a restorative material mainly in the posterior region. The main problem associated with ceramic restorations is their lower resistance to fracture, especially for FPDs in the posterior region [3, 13-15]. Zirconia has demonstrated excellent mechanical properties [16, 17]. It appears to be a promising alternative for posterior restorations, where an average posterior bite force of $700 \mathrm{~N}$ has been recorded, with a 
maximum of approximately $900 \mathrm{~N}$ [18-23]. However, the main problem associated with first-generation zirconia restorations was porcelain chipping with fracture rate higher than MC restorations [1]. Several factors have been involved in the chipping of zirconia restorations as the thermal compression and expansion forces resulting from the sintering process and the differences in the modulus of elasticity between the core and the veneering ceramic [20,24], the alteration of the zirconia crystalline structure during surface treatments of frameworks, that induced cracks [1] an increase in temperature and a change in the coefficient of expansion $[1,14$, 25-27]. Chipping has also been associated with an inadequate thickness of the veneering ceramic, and therefore, an anatomical core design was recommended [28, 29].

Monolithic zirconia restorations have been developed to overcome the chipping problem. Monolithic zirconia presents several advantages as less manufacturing time and less tooth preparation compared to veneered zirconia [30, 31]. However, clinical studies that evaluated the behavior in posterior regions are sparse.

Therefore, the aim of this prospective randomized clinical trial (RCT) was to evaluate and to compare the survival and success rates, as well as the biological and technical complications of 3-unit veneered and monolithic zirconia posterior FPDs. The null hypothesis tested was that no differences between the groups would be found among the studied parameters.

\section{Material and methods}

\section{Patient selection}

To carry out the present RCT, a total of 82 patients requiring a 3-unit posterior FPD were screened and examined. Out of the 82 patients, sixty ( 38 women, 22 men) fulfilled the inclusion criteria and were enrolled in the study. The study was conducted at the dental clinic of the Master in Bucofacial Prosthesis and Occlusion (Faculty of Odontology, University Complutense of Madrid, Spain). No power analysis was carried out, and the sample size was determined based on previous studies $[6,12,14,29,31]$. The age of the subjects ranged from 24 to 72 years.

Before treatment, patients were informed of the study objectives, clinical procedure, materials used, the risks and benefits of ceramic restorations, and the therapeutic alternatives. All patients signed an informed consent to participate in the study. The study was conducted in accordance with the Declaration of Helsinki, and the protocol was approved by the Ethical Committee of Clinical Trial at S. Carlos University Clinical Hospital (Madrid, Spain) (C.P.- C.I. 15/236E). The study was registered in ClinicalTrials.gov (Identifier
NCT 04,879,498). Patients were treated between September 19, 2016, and May 20, 2017.

The patients were randomly distributed (www.alazar.info) into two groups $(n=30$ each) to receive either monolithic or veneered zirconia FPDs. Therefore, 60 posterior FPDs were produced and allocated in parallel to either monolithic second-generation zirconia using the Zenostar T system (Wieland Dental, Pforzheim, Germany) $(n=30)$ or veneered first-generation zirconia using the IPS e.max ZirCAD system (Ivoclar Vivadent, Schaan, Liechtenstein) $(n=30)$ (Fig. 1). Thirty-three FPDs were placed in the maxilla, and 27 were placed in the mandible (Table 1). The patients did not know which treatment they were receiving.

The inclusion criteria were as follows: one posterior tooth (molar or premolar) to be replaced, vital abutments or with adequate endodontic treatment, not previously crowned, periodontally healthy abutments, occlusal-gingival height suitable for a connector of at least $9 \mathrm{~mm}^{2}$, stable occlusion,

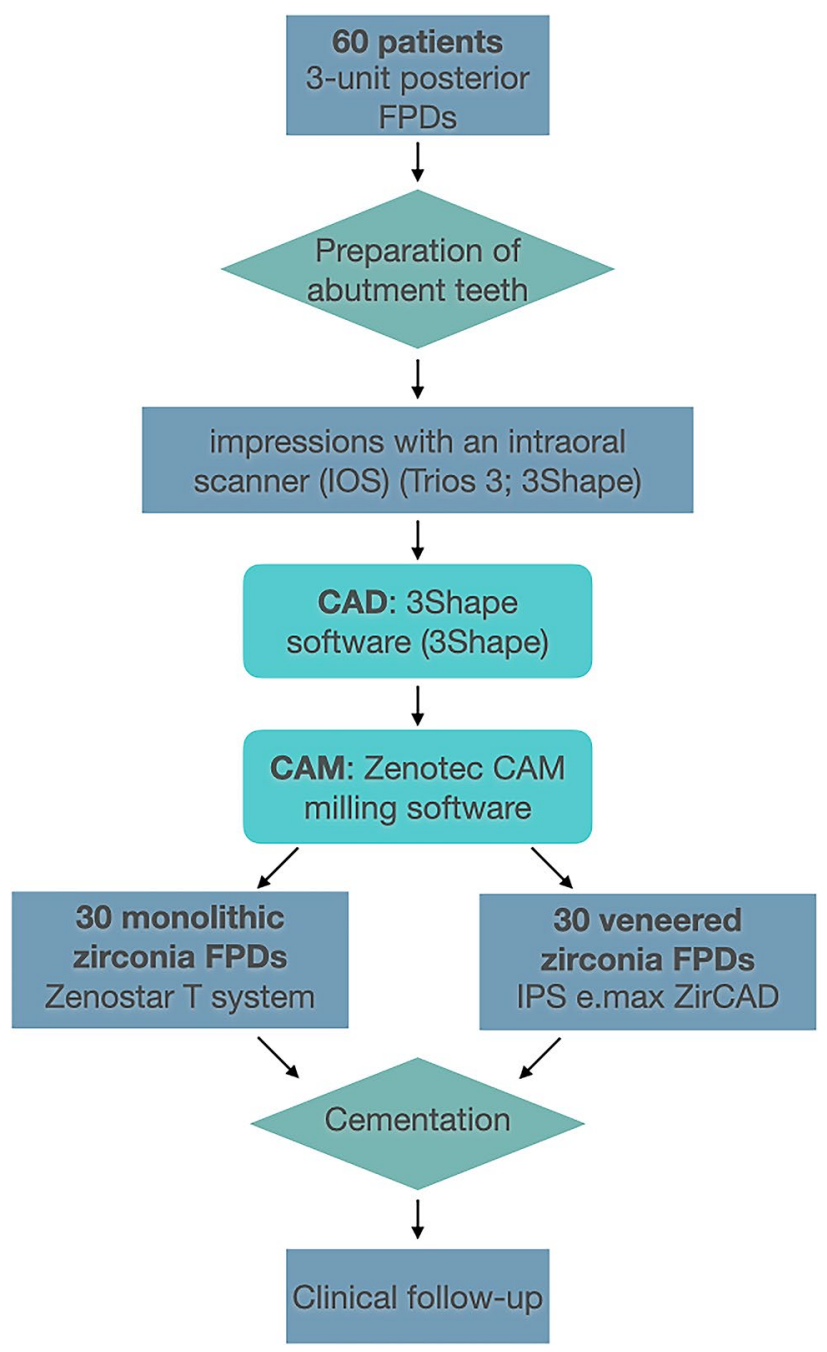

Fig. 1 CONSORT flowchart 
Table 1 Patient demographics (\%)

\begin{tabular}{llll}
\hline & All groups & Monolithic zirconia & Veneered zirconia \\
\hline Patients & $60(100)$ & $30(50)$ & $30(50)$ \\
Mean age (range) & $56(24-72)$ & $54(24-68)$ & $58(28-72)$ \\
Male & $22(37)$ & $13(22)$ & $9(15)$ \\
Female & $38(63)$ & $17(28)$ & $21(35)$ \\
Jaw & & & \\
Maxilla & $33(55)$ & $20(33)$ & $13(22)$ \\
Mandibula & $27(45)$ & $10(17)$ & $17(28)$ \\
Replaced teeth & & & $23(38)$ \\
2nd premolar & $35(58)$ & $12(20)$ & $7(12)$ \\
1st molar & $25(42)$ & $18(30)$ & $14(23)$ \\
Endodonthic treatment & $24(40)$ & $10(17)$ & \\
\hline
\end{tabular}

and the presence of natural dentition in the opposing arch. The exclusion criteria consisted of patients requiring a FPD of more than three units, a reduced crown length (less than $3 \mathrm{~mm}$ occluso-gingival height), poor oral hygiene, active cavities, and active periodontal disease. The presence of probable bruxism was recorded based on a positive clinical inspection [32].

\section{Clinical and laboratory procedures}

The clinical procedures were performed by two experienced clinicians. The abutment teeth were prepared as follows: circumferential chamfer ( 0.8 to $1 \mathrm{~mm}$ wide), an axial reduction of $1 \mathrm{~mm}$, and occlusal reduction of $1.5 \mathrm{~mm}$, and a 10 to $12^{\circ}$ convergence of the axial walls [12,31]. Before impression taking, a dental gingival cord was placed in the gingival sulcus. Digital impressions were taken using an intraoral scanner (IOS) (Trios 3, 3Shape, Copenhagen, Denmark). Provisional restorations (Telio CS C\&B, Ivoclar Vivadent, Schaan, Liechtenstein) were fabricated and cemented using a temporary cement (Telio CS Link, Ivoclar Vivadent). The shade was selected using the Chromascop Shade Guide (Ivoclar Vivadent).

All FPDs were designed using 3Shape software (Dental System 2016, 3Shape). The axial wall thickness for monolithic and veneered zirconia restorations was set at $1 \mathrm{~mm}$ and $0.5 \mathrm{~mm}$, respectively. The thickness at the occlusal surface was set at $1.5 \mathrm{~mm}$ for monolithic and at $0.8 \mathrm{~mm}$ for the veneered zirconia frameworks, which were designed with an anatomic shape. In both groups, the dimensions of the connectors were $9 \mathrm{~mm}^{2}$, following the manufacturer's recommendations, and an internal space for the cement was set at $0.05 \mathrm{~mm}$. The information was sent to the Zenotec CAM milling software (Zenotec CAM 3.2, Wieland Dental, Pforzheim, Germany). All FPDs were milled from presintered zirconia blanks in the Wieland Zenotec unit (Wieland Dental) and sintered in a furnace (Programat S1 1600, Ivoclar Vivadent). The monolithic zirconia restorations

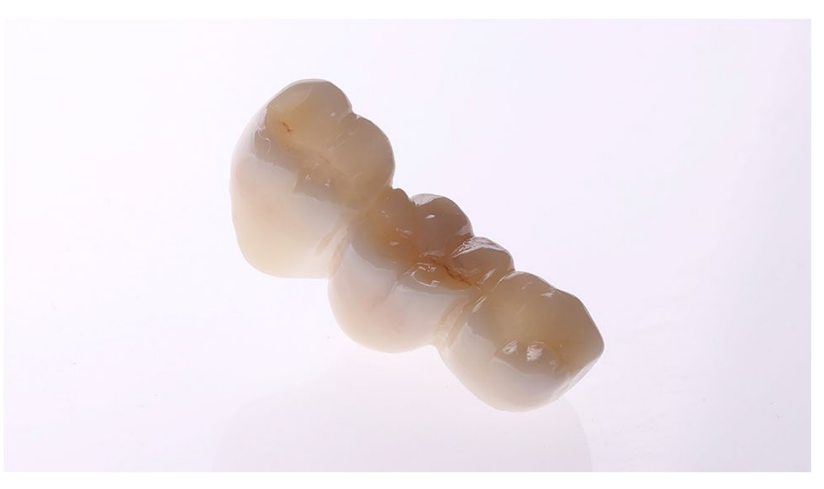

Fig. 2 Final monolithic zirconia restoration

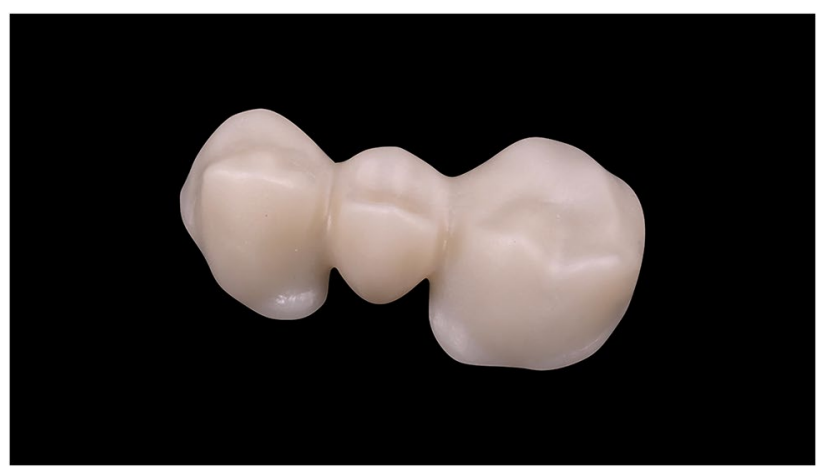

Fig. 3 IPS e.max ZirCAD framework

were sintered at $1.450{ }^{\circ} \mathrm{C}$ for $4 \mathrm{~h} 50 \mathrm{~min}$. Once sintered, the restorations were characterized with Ivocolor Stains and glazed with Ivocolor Glaze Paste FLUO (Ivoclar Vivadent) at $710{ }^{\circ} \mathrm{C}$, with a heating rate of $45^{\circ} \mathrm{C} / \mathrm{min}$, and long-term cooling to $450{ }^{\circ} \mathrm{C}$, following the manufacturer's instructions (Fig. 2). In the monolithic zirconia group, an intermediate polymethyl methacrylate try-in was performed before milling the FPDs. Veneered zirconia restorations were sintered at $1.500{ }^{\circ} \mathrm{C}$ for $9 \mathrm{~h} 50 \mathrm{~min}$ (Fig. 3) and mouth-tested to check 
the fit. Before veneering the frameworks, 3D printed casts were fabricated with a 3D printer (MAX, Asiga, Sydney, Australia) and a 3D printable resin (Dental Model, Asiga). The frameworks were then veneered with the corresponding hand-layered veneering ceramic (IPS e.max Ceram, Ivoclar Vivadent). The layering porcelain thickness was approximately $0.5 \mathrm{~mm}$ at the axial walls and $0.7 \mathrm{~mm}$ at the occlusal surface. All the restorations were fabricated by the same experienced technician who verified the thickness of the veneering porcelain using a digital micrometer.

The inner surface of the FPDs were carefully sandblasted with $50 \mu \mathrm{m}$ silica-modified alumina particles at a pressure of $0.28 \mathrm{MPa}$, at $10 \mathrm{~mm}$ for $20 \mathrm{~s}$ (CoJet Sand, $3 \mathrm{M}$ ESPE, Seefeld, Germany), mouth-tested, cleaned with a universal cleaning paste (Ivoclean, Ivoclar Vivadent), and all the restorations were then cemented using a resin selfadhesive cement (SpeedCEM, Ivoclar Vivadent) (Fig. 4). After cementation, occlusal contacts were evaluated, and the adjusted surfaces were polished with a porcelain polishing kit (Optrafine, Ivoclar Vivadent) [31]. The patients were instructed in oral hygiene education at the end of the treatment and at each recall visit.

\section{Clinical follow-up protocol}

The restorations were evaluated according to the California Dental Association (CDA) assessment system [6, 10-14, 28, 33]. The periodontal parameters were examined using the plaque index (PI), gingival index (GI), pocket depth, and margin index (MI) of all abutment and control teeth (contralateral or opposite not crowned teeth) $[6,12,31]$. All FPDs were examined at 1 week (baseline) and 1, 2, and 3 years after the end of the treatment by 2 calibrated examiners who were not involved in the restorative treatment. Each examiner evaluated the restorations independently, and the worst outcome was used in the event of discrepancies. Parallelized periapical radiographs of the abutment teeth were taken using an X-ray positioner (Rinn, Dentsply Sirona,

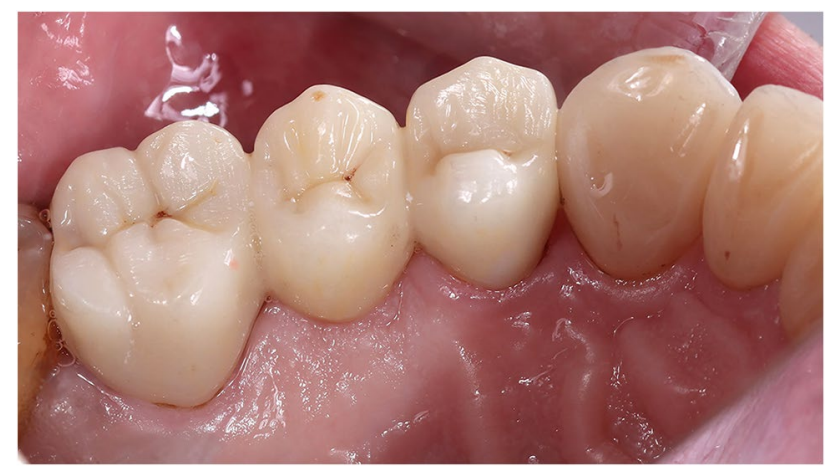

Fig. 4 Clinical view of a maxillary posterior monolithic zirconia FPD after cementation
Charlotte, NC, USA), and clinical photographs of the restorations were obtained under standardized conditions at each evaluation. The primary outcome measures were the survival and success rates. The secondary outcomes included the CDA ratings, technical and biological complications, and the periodontal assessment. Success was defined as the absence of complications on the FPDs during the entire follow-up period, and survival was defined as the permanence of the FPDs in situ at each follow-up recall $[25,34]$.

\section{Statistical analysis}

Descriptive statistics were used to evaluate clinical outcomes. The Wilcoxon signed-rank test with the Bonferroni correction was used to compare variables for matched pairs on FPDs to evaluate differences considering the CDA ratings, periodontal parameters, and for comparisons of periodontal parameters between abutment and control teeth. The comparisons of the baseline and the follow-up values were performed by the Friedman test. The Mann-Whitney $\mathrm{U}$ test was used to compare variables between both groups. Survival rates were determined based on the CDA criteria. Each CDA criterion was ranked on a scale of 1 to 4 , where $4=$ excellent, $3=$ good, $2=$ unacceptable (repair), and $1=$ unacceptable (replacement). The periodontal parameters were assessed by assigning a score of 0 to 3 (PI and GI), or 1 to 4 (MI and pocket depth). Statistical software (IBM SPSS Statistics 22.0, IBM Corp, Armonk, NY, USA) was used for the analysis and statistical significance was established at $\alpha=0.05$.

\section{Results}

A total of 60 patients received 60 three-unit FPDs (30 veneered and 30 monolithic zirconia). No participants were lost during the observation period $(40 \pm 2.6$ months). Nine patients $(15 \%)$ with probable bruxism were included in the study: 5 in the veneered zirconia group and 4 in the monolithic zirconia group. The survival rate for the veneered zirconia restorations was $100 \%$, whereas that for the monolithic zirconia restorations was $90 \%$. The success rate was $86.7 \%$ for the veneered zirconia due to the chipping of the veneering ceramic, and $90 \%$ for the monolithic zirconia FPDs due to biological complications. Three biologic complications were found at the 3-year follow-up in monolithic restorations: two vertical fractures in one of the abutment teeth which required extraction and one secondary caries that made it necessary to remove the restorations. One of the abutment fractures occurred in a bruxist patient. No fractures of zirconia frameworks were observed during the observation period. 
All restorations from both groups were assessed as satisfactory. Deviations from the score of excellent are presented in Fig. 5a-c. The percentage of chipping increased from zero at baseline to $6.6 \%$ and $13.3 \%$ after 2 and 3 years, respectively. However, the zirconia frameworks remained covered, and remaking of the restorations was not necessary. Surface roughness was observed in 4 FPDs of each group from baseline. A significant change was observed within the veneered zirconia restorations from baseline to the 3-year follow-up evaluation $(p=0.008)$. No differences were observed between the two groups for surface and color. With respect to anatomical form, one (3.7\%) monolithic zirconia restoration and six (20\%) veneered zirconia were assessed as acceptable at the 3-year follow-up evaluation due to wear at the occlusal surface, slightly over-contoured restorations, or contact areas slightly opened. There were no significant changes within each group from baseline to the 3 -year follow-up evaluation. Significant differences $(p=0.04)$ were observed between both groups at the 2-year follow-up. The marginal integrity was ranked as excellent in $93 \%$ for both types of zirconia restorations. Margin discoloration with no evidence of caries was the reason for changes form excellent
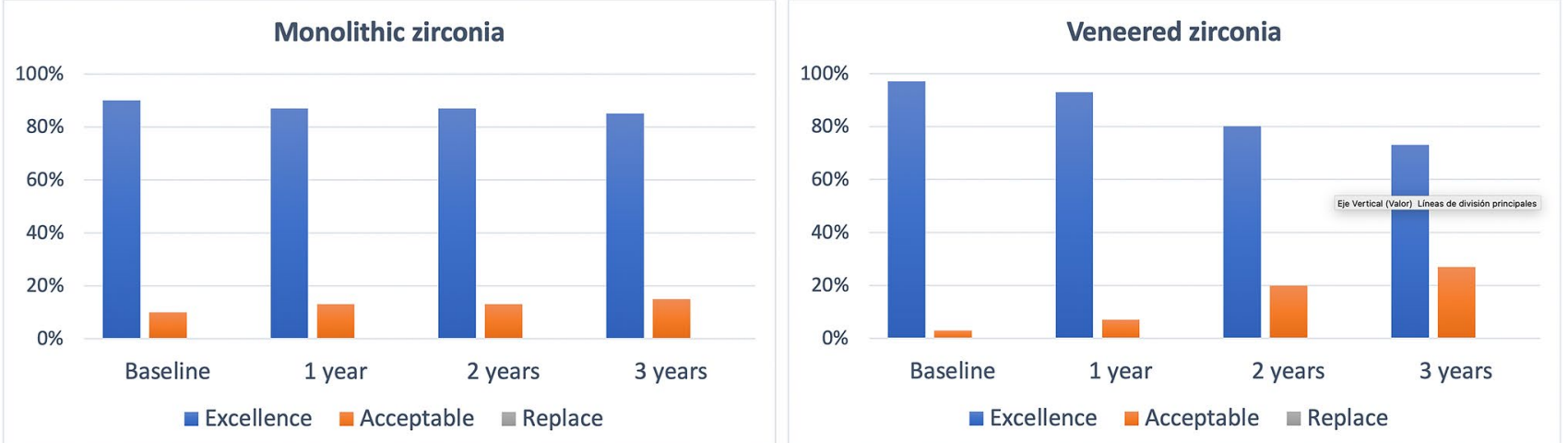

a
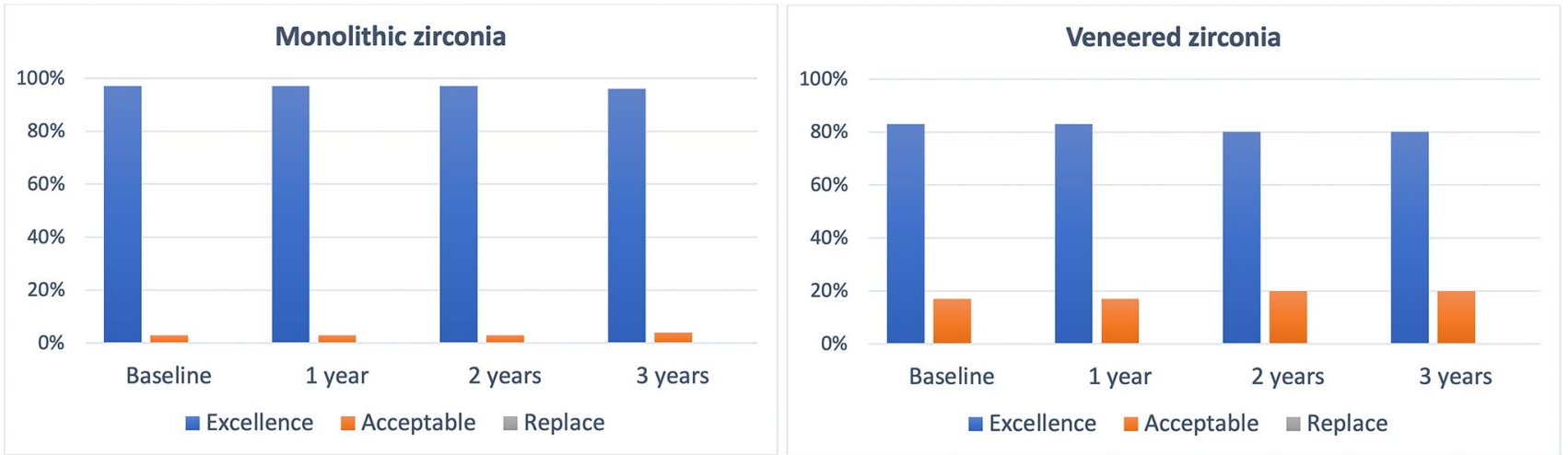

b
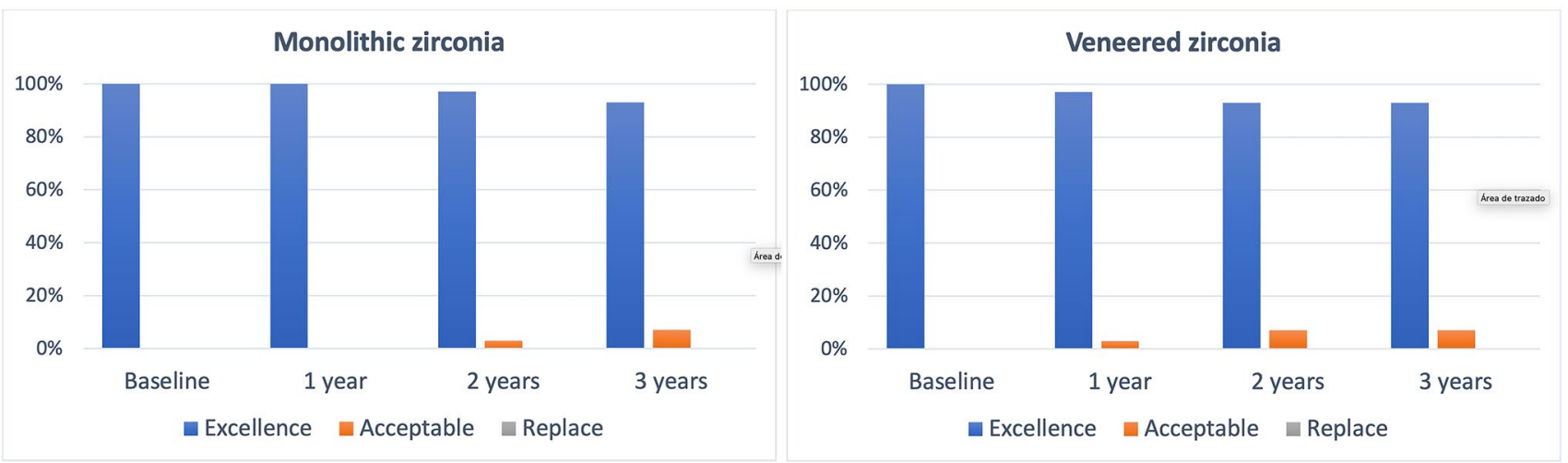

c

Fig. 5 Results for CDA criteria at baseline, 1-, 2-, and 3-year follow-up evaluations for monolithic and veneered zirconia FPDs. a Surface and color. b Anatomic form. c Margin integrity 
to acceptable in both groups. No differences were observed within each group and between both groups from baseline to the 3-year follow-up evaluation.

Periodontal parameters are summarized in Table 2. No differences were observed in the abutment teeth from baseline to the 3-year follow-up evaluation within each group or between both groups with regard to PI, GI, and pocket depth. Likewise, no differences were shown of the abutment and control teeth at both groups. The MI remained stable throughout the follow-up period within each group.

\section{Discussion}

This study analyzed the clinical performance and survival and success rates of 3-unit monolithic and veneered zirconia FPDs. The data obtained support the partial rejection of the null hypothesis since significant differences were observed between both groups in anatomical form at the 2-year follow-up evaluation.

The survival rate for monolithic zirconia FPDs was $90 \%$. Three FPDs were lost because of biologic complications. It is important to emphasize that due to the global situation caused by COVID-19, the patients have been subjected to an important stress for months. The results are consistent with previous studies in monolithic zirconia crowns that reported survival rates in the range of 91.5 to $100 \%$ [10, 35-42]. However, studies on posterior monolithic zirconia FPDs are scarce. Two- and 3-year follow-up studies have shown survival rates higher than the finding of the study (96.7 to 100\%) [31, 43, 44]. The survival rates for veneered zirconia were $100 \%$ after 3 years, consistent with previous findings [5, 8, 11, 12, 45-47]. However, the success rate was $86.7 \%$ due to veneer chipping fractures. This was the main complication in veneered zirconia FPDs as previously reported [5, 6, 11, 12, 14, 46-48], although the zirconia framework remained covered. The fractures could be polished without affecting the function or esthetic consistent with previous findings [5, 6, 11-14, 24, 31, 48]. Although the minimum material thickness recommended by the manufacturer for monolithic zirconia was $0.6-0.8 \mathrm{~mm}$, in the study, an axial reduction of $1 \mathrm{~mm}$ and an occlusal reduction of $1.5 \mathrm{~mm}$ was performed. Reduced abutment tooth preparation is an advantage of monolithic zirconia restoration; however, insufficient interocclusal space can lead to the failure of the monolithic zirconia restoration [42].

According to the CDA scores, all restorations were assessed as satisfactory at the 3-year follow-up evaluation. Small deviations from the score of excellent regarding surface and color, anatomic form, and margin integrity were observed from baseline to the 3-year follow-up evaluation; however, no differences were observed from baseline within each group. This is consistent with previous studies [5, 6, $11-14,24,31,48]$. Nevertheless, differences in anatomical form were observed between the groups at the 2-year followup evaluation. This could be explained because of contact area slightly opened in one veneered zirconia FPDs.

No fracture of the frameworks was observed in any of the groups consistent with previous systematic reviews on zirconia posterior FPDs [25]. This could be due to the stability of the zirconia as a structural material [25] and to the dimension of the connector area $\left(9 \mathrm{~mm}^{2}\right)[12,31]$. In the study, no decementation, abutment sensitivity, or abutment loss of vitality was observed in either group, which is consistent with previous studies [12, 14, 31, 49].

At the 3-year time point, a good response in the soft tissues was observed in both groups with no differences thorough the observation period within the groups, between the
Table 2 Periodontal parameters assessments at baseline (B), 1-, 2-, and 3-year follow-up evaluations for monolithic and veneered zirconia FPDs

\begin{tabular}{|c|c|c|c|c|c|c|c|c|c|c|c|c|c|c|c|c|c|}
\hline & \multirow[b]{3}{*}{ Score } & \multicolumn{8}{|c|}{ Monolithic zirconia } & \multicolumn{8}{|c|}{ Veneered zirconia } \\
\hline & & \multicolumn{4}{|c|}{ Abutment teeth } & \multicolumn{4}{|c|}{ Control teeth } & \multicolumn{4}{|c|}{ Abutment teeth } & \multicolumn{4}{|c|}{ Control teeth } \\
\hline & & B & 1 & 2 & 3 & B & 1 & 2 & 3 & B & 1 & 2 & 3 & B & 1 & 2 & 3 \\
\hline \multirow[t]{4}{*}{ Plaque index } & 0 & 20 & 20 & 19 & 15 & 21 & 18 & 20 & 14 & 21 & 23 & 20 & 17 & 24 & 22 & 18 & 17 \\
\hline & 1 & 6 & 7 & 7 & 8 & 7 & 11 & 8 & 11 & 7 & 6 & 8 & 10 & 5 & 8 & 12 & 12 \\
\hline & 2 & 4 & 3 & 4 & 4 & 2 & 1 & 2 & 2 & 2 & 1 & 2 & 3 & 1 & 0 & 0 & 1 \\
\hline & 3 & 0 & 0 & 0 & 0 & 0 & 0 & 0 & 0 & 0 & 0 & 0 & 0 & 0 & 0 & 0 & 0 \\
\hline \multirow[t]{4}{*}{ Gingival index } & 0 & 21 & 22 & 20 & 17 & 21 & 20 & 20 & 17 & 23 & 20 & 21 & 19 & 24 & 20 & 16 & 19 \\
\hline & 1 & 7 & 5 & 6 & 7 & 9 & 8 & 8 & 8 & 5 & 9- & 7 & 10 & 5 & 9 & 13 & 10 \\
\hline & 2 & 2 & 3 & 4 & 3 & 0 & 2 & 2 & 2 & 2 & 1 & 2 & 1 & 1 & 1 & 1 & 1 \\
\hline & 3 & 0 & 0 & 0 & 0 & 0 & 0 & 0 & 0 & 0 & 0 & 0 & 0 & 0 & 0 & 0 & 0 \\
\hline \multirow[t]{4}{*}{ Pocket depth } & 1 & 22 & 23 & 21 & 19 & 23 & 20 & 20 & 19 & 23 & 23 & 21 & 20 & 25 & 24 & 22 & 21 \\
\hline & 2 & 8 & 7 & 9 & 8 & 7 & 10 & 10 & 8 & 7 & 7 & 9 & 10 & 5 & 6 & 8 & 9 \\
\hline & 3 & 0 & 0 & 0 & 0 & 0 & 0 & 0 & 0 & 0 & 0 & 0 & 0 & 0 & 0 & 0 & 0 \\
\hline & 4 & 0 & 0 & 0 & 0 & 0 & 0 & 0 & 0 & 0 & 0 & 0 & 0 & 0 & 0 & 0 & 0 \\
\hline
\end{tabular}


groups, and among abutment and control teeth. The results are consistent with previous findings $[31,33,50]$, but contradictory to other studies that reported an increased risk of gingivitis in the vicinity of a fixed prosthesis, and differences from baseline in the periodontal parameters [11, 12, 14]. The findings of the study could be due to the good plaque control, the good marginal fit of both type of zirconia restorations, and the excellent biocompatibility of zirconia [51].

The introduction of digital technology has allowed the fabrication of dental restorations to become more automated, more time efficient, and accurate. Digital workflow has shown results comparable to those obtained with conventional techniques. One of the parameters associated with the success of restorations is the marginal fit, along with resistance to fracture, and studies have shown excellent results for restorations made with a digital flow $[31,41,52$, 53]. However, several factors can affect the accuracy of the prostheses, such as the software version, the experience of both the clinician and the technician, and the adjustment parameters. In the study, a complete digital workflow was performed with patient satisfaction, reduction time, and clinically satisfying outcomes as previously reported [29, $31,39,52-54]$. However, clinical evidence is scarce and further studies are necessary [31,54].

The limitations of the study were that no power analysis was performed to determine the sample size and the short observation period. Nevertheless, the results of the study suggest that monolithic zirconia and complete digital flow could be a viable alternative to veneered zirconia in the posterior regions. However, additional randomized clinical trial studies comparing both types of restorations with a longer observational period are needed.

\section{Conclusions}

Within the limitations of the present study, the 3-year results suggest that monolithic zirconia restorations fabricated in a complete digital flow are a viable alternative to veneered zirconia restorations in the posterior regions avoiding the chipping problem.

\footnotetext{
Acknowledgements The authors would like to thank the dental laboratory 3Dental CAD-CAM for the technical advice and for the manufacturing of the restorations, and Dr. Carmen Bravo, Centre for Data Processing, Computing Service for Research Support of the Complutense University of Madrid (UCM), for her assistance with the statistical analysis.
}

Author contribution All the authors contributed to the study, writing, review, and editing of the manuscript. Conceptualization: MJS and JP; Methodology: PP, CLS, VR, JP, and MJS; Formal analysis and investigation: PP, CLS, VR, JP, and MJS; Writing-original draft preparation, review, and editing: PP, CLS, VR, JP, and MJS. Supervision: MJS. All authors approved the final manuscript.
Funding This work was partially supported by a research grant between the University Complutense of Madrid (UCM) and Ivoclar Vivadent AG (No. 54-2015).

\section{Declarations}

Ethics approval All procedures performed in studies involving human participants were in accordance with the ethical standards of the institutional and/or national research committee and with the 1964 Helsinki Declaration and its later amendments or comparable ethical standards. The study was approved by the Ethical Committee of Clinical Trial at San Carlos University Clinical Hospital in Madrid (C.P.- C.I. 15/236E).

Informed consent Informed consent was obtained from all individual participants included in the study.

Conflict of interest The authors declare no competing interests.

\section{References}

1. Heintze SD, Rousson V (2010) Survival of zirconia and metalsupported fixed dental prostheses: a systematic review. Int J Prosthodont 23:493-502

2. Larsson C, Wennerberg A (2014) The clinical success of zirconiabased crowns: a systematic review. Int J Prosthodont 27:33-43. https://doi.org/10.11607/ijp.3647

3. Monaco C, Caldari M, Scotti R (2015) Clinical evaluation of tooth-supported zirconia-based fixed dental prostheses: a retrospective cohort study from the AIOP clinical research group. Int J Prosthodont 28:236-8. https://doi.org/10.11607/ijp.4023

4. Wolfart S, Eschbach S, Scherrer S, Kern M (2009) Clinical outcome of three-unit lithium-disilicate glass-ceramic fixed dental prostheses: up to 8 years results. Dent Mater 25:63-71. https:// doi.org/10.1016/j.dental.2009.05.003

5. Sailer I, Balmer M, Husler J, Hammerle CHF, Kanel S, Thoma DS (2017) Comparison of fixed dental prostheses with zirconia and metal frameworks: five-year results of a randomized controlled clinical trial. Int J Prosthodont 30:426-8. https://doi.org/10.11607/ ijp. 5183

6. Pelaez J, Cogolludo PG, Serrano B, Serrano JFL, Suarez MJ (2012) A four-year prospective clinical evaluation of zirconia and metal-ceramic posterior fixed dental prostheses. Int J Prosthodont 25:451-458

7. Walton TR (2002) An up to 15-year longitudinal study of 515 metal-ceramic FPDs: Part 1. Outcome Int J Prosthodont 15:439-445

8. Zarone F, Russo S, Sorrentino R (2011) From porcelain-fused-tometal to zirconia: clinical and experimental considerations. Dent Mater 27:83-96. https://doi.org/10.1016/j.dental.2010.10.024

9. Freire Y, Gonzalo E, Lopez-Suarez C, Suarez MJ (2019) The marginal fit of CAD/CAM monolithic ceramic and metal-ceramic crowns. J Prosthodont 28:299-304. https://doi.org/10.1111/jopr. 12590

10. Tang Z, Zhao X, Wang H, Liu B (2019) Clinical evaluation of monolithic zirconia crowns for posterior teeth restorations. Medicine (Baltimore) 98:e17385. https://doi.org/10.1097/MD.00000 00000017385

11. Nicolaisen MH, Bahrami G, Schropp L, Isidor F (2016) Comparison of metal-ceramic and all-ceramic three-unit posterior fixed dental prostheses: a 3-year randomized clinical trial. Int J Prosthodont 29:259-64. https://doi.org/10.11607/ijp.4504 
12. Suarez MJ, Perez C, Pelaez J, Lopez-Suarez C, Gonzalo E (2019) A randomized clinical trial comparing zirconia and metal-ceramic three-unit posterior fixed partial dentures: a 5-year follow-up. J Prosthodont 28:750-756. https://doi.org/10.1111/jopr.12952

13. Sailer I, Pjetursson BE, Zwahlen M, Hammerle CHF (2007) A systematic review of the survival and complication rates of allceramic and metal-ceramic reconstructions after an observation period of at least 3 years Part II: Fixed dental prostheses. Clin Oral Implants Res 18(Suppl 3):86-96. https://doi.org/10.1111/j. 1600-0501.2007.01468.x

14. Pelaez J, Cogolludo PG, Serrano B, Lozano JFL, Suarez MJ (2012) A prospective evaluation of zirconia posterior fixed dental prostheses: three-year clinical results. J Prosthet Dent 107:373379. https://doi.org/10.1016/S0022-3913(12)60094-8

15. Lopez-Suarez C, Gonzalo E, Pelaez J, Rodriguez V, Suarez MJ (2015) Fracture resistance and failure mode of posterior fixed dental prostheses fabricated with two zirconia CAD/CAM systems. J Clin Exp Dent 7:e250-253. https://doi.org/10.4317/jced.52067

16. Vidotti HA, Pereira JR, Insaurralde E, de Almeida ALPF, do Valle AL (2013) Thermo and mechanical cycling and veneering method do not influence Y-TZP core/veneer interface bond strength. J Dent 41:307-312. https://doi.org/10.1016/j.jdent.2012.12.001

17. Lopez-Suarez C, Tobar C, Sola-Ruiz MF, Pelaez J, Suarez MJ (2019) Effect of thermomechanical and static loading on the load to fracture of metal-ceramic, monolithic, and veneered zirconia posterior fixed partial dentures. J Prosthodont 28:171-178. https:// doi.org/10.1111/jopr.13008

18. Sun T, Zhou S, Lai R, Liu R, Ma S, Zhou Z et al (2014) Loadbearing capacity and the recommended thickness of dental monolithic zirconia single crowns. J Mech Behav Biomed Mater 35:93-101. https://doi.org/10.1016/j.jmbbm.2014.03.014

19. Rodriguez V, Castillo-Oyague R, Lopez-Suarez C, Gonzalo E, Pelaez J, Suarez-Garcia M-J (2016) Fracture load before and after veneering zirconia posterior fixed dental prostheses. J Prosthodont 25:550-556. https://doi.org/10.1111/jopr.12357

20. Komine F, Blatz MB, Matsumura H (2010) Current status of zirconia-based fixed restorations. J Oral Sci 52:531-539. https:// doi.org/10.2334/josnusd.52.531

21. Raigrodski AJ, Yu A, Chiche GJ, Hochstedler JL, Mancl LA, Mohamed SE (2012) Clinical efficacy of veneered zirconium dioxide-based posterior partial fixed dental prostheses: five-year results. J Prosthet Dent 108:214-222. https://doi.org/10.1016/ S0022-3913(12)60165-6

22. Castillo Oyague R, Sanchez-Jorge MI, Sanchez TA (2010) Influence of CAD/CAM scanning method and tooth-preparation design on the vertical misfit of zirconia crown copings. Am J Dent 23:341-346

23. Agustin-Panadero R, Fons-Font A, Roman-Rodriguez JL, GranellRuiz M, del Rio-Highsmith J, Sola-Ruiz MF (2012) Zirconia versus metal: a preliminary comparative analysis of ceramic veneer behavior. Int J Prosthodont 25:294-300

24. Sailer I, Gottnerb J, Kanelb S, Hammerle CHF (2009) Randomized controlled clinical trial of zirconia-ceramic and metalceramic posterior fixed dental prostheses: a 3-year follow-up. Int J Prosthodont 22:553-560

25. Pjetursson BE, Sailer I, Makarov NA, Zwahlen M, Thoma DS (2015) All-ceramic or metal-ceramic tooth-supported fixed dental prostheses (FDPs)? A systematic review of the survival and complication rates. Part II: Multiple-unit FDPs Dent Mater 31:624639. https://doi.org/10.1016/j.dental.2015.02.013

26. Ashkanani HM, Raigrodski AJ, Flinn BD, Heindl H, Mancl LA (2008) Flexural and shear strengths of $\mathrm{ZrO} 2$ and a high-noble alloy bonded to their corresponding porcelains. J Prosthet Dent 100:274-284. https://doi.org/10.1016/S0022-3913(08)60206-1

27. Esquivel JF, Kim MJ, Hsu S, Abdulhameed N, Jenkins R, Neal D et al (2018) Randomized clinical study of wear of enamel antagonists against polished monolithic zirconia crowns. J Dent 68:19-27. https://doi.org/10.1016/j.jdent.2017.10.005

28. Tartaglia GM, Sidoti E, Sforza C (2015) Seven-year prospective clinical study on zirconia-based single crowns and fixed dental prostheses. Clin Oral Investig 9:1137-1145. https://doi.org/10. 1007/s00784-014-1330-2

29. Selz CF, Bogler J, Vach K, Strub JR, Guess PC (2015) Veneered anatomically designed zirconia FDPs resulting from digital intraoral scans: Preliminary results of a prospective clinical study. J Dent 43:1428-1435. https://doi.org/10.1016/j.jdent. 2015.10.017

30. Freire Y, Gonzalo E, Lopez-Suarez C, Pelaez J, Suarez MJ (2020) Evaluation of the marginal fit of monolithic crowns fabricated by direct and indirect digitization. J Prosthodont Res. https://doi.org/ 10.2186/jpr.JPR_D_20_00003

31. Pontevedra P, Lopez-Suarez C, Pelaez J, Garcia-Serdio S, Suarez MJ (2021) Prospective clinical evaluation of posterior monolithic zirconia fixed partial dentures using a complete digital workflow: two-year follow-up. J Prosthodont 30:298-304. https://doi.org/10. 1111/jopr.13251

32. Lobbezoo F, Ahlberg J, Raphael KG, Wetselaar P, Glaros AG, Kato $T$ et al (2018) International consensus on the assessment of bruxism: report of a work in progress. J Oral Rehabil 45:837-844. https://doi.org/10.1111/joor.12663

33. Schmitz JH, Cortellini D, Granata S, Valenti M (2017) Monolithic lithium disilicate complete single crowns with feather-edge preparation design in the posterior region: a multicentric retrospective study up to 12 years. Quintessence Int 1985:601-608. https://doi. org/10.3290/j.qi.a38678

34. Sailer I, Strasding M, Valente NA, Zwahlen M, Liu S, Pjetursson BE (2018) A systematic review of the survival and complication rates of zirconia-ceramic and metal-ceramic multiple-unit fixed dental prostheses. Clin Oral Implants Res 29(Suppl 16):184-198. https://doi.org/10.1111/clr.13277

35. Konstantinidis I, Trikka D, Gasparatos S, Mitsias ME. (2018) Clinical outcomes of monolithic zirconia crowns with CAD/CAM technology. a 1-year follow-up prospective clinical study of 65 patients. Int J Environ Res Public Health 15. https://doi.org/10. 3390/ijerph15112523

36. Pathan MS, Kheur MG, Patankar AH, Kheur SM (2019) Assessment of antagonist enamel wear and clinical performance of fullcontour monolithic zirconia crowns: one-year results of a prospective study. J Prosthodont 28:e411-e416. https://doi.org/10.1111/ jopr.12960

37. Kitaoka A, Akatsuka R, Kato H, Yoda N, Sasaki K (2018) Clinical evaluation of monolithic zirconia crowns: a short-term pilot report. Int J Prosthodont 31:124-6

38. Batson ER, Cooper LF, Duqum I, Mendonça G (2014) Clinical outcomes of three different crown systems with CAD/CAM technology. J Prosthet Dent 112:770-777. https://doi.org/10.1016/j. prosdent.2014.05.002

39. Bömicke W, Rammelsberg P, Stober T, Schmitter M (2017) Shortterm prospective clinical evaluation of monolithic and partially veneered zirconia single crowns. J Esthet Restor Dent 29:22-30. https://doi.org/10.1111/jerd.12270

40. Gunge H, Ogino Y, Kihara M, Tsukiyama Y, Koyano K (2018) Retrospective clinical evaluation of posterior monolithic zirconia restorations after 1 to 3.5 years of clinical service. J Oral Sci 60:154-158. https://doi.org/10.2334/josnusd.17-0176

41. Solá-Ruiz M, Baixauli-López M, Roig-Vanaclocha A, Amengual J, Agustín-Panadero R (2021) Prospective study of monolithic zirconia crowns: clinical behavior and survival rate at a 5-year follow-up. J Prosthodont Res. https://doi.org/10.2186/jpr.JPR_D_ 20_00034

42. Miura S, Yamauchi S, Kasahara S, Katsuda Y, Fujisawa M, Egusa $\mathrm{H}$ (2020) Clinical evaluation of monolithic zirconia crowns: a 
failure analysis of clinically obtained cases from a 35-year study. J Prosthodont Res 5:5246

43. Koenig V, Wulfman C, Bekaert S, Dupont N, Le Goff S, Eldafrawy M et al (2019) Clinical behavior of second-generation zirconia monolithic posterior restorations: two-year results of a prospective study with ex vivo analyses including patients with clinical signs of bruxism. J Dent 91:103229. https://doi.org/10. 1016/j.jdent.2019.103229

44. Habibi Y, Dawid M, Waldecker M, Rammelsberg P, Bömicke W (2020) Three-year clinical performance of monolithic and partially veneered zirconia ceramic fixed partial dentures. J Esthet Restor Dent 32:395-402. https://doi.org/10.1111/jerd.12568

45. Pihlaja J, Näpänkangas R, Raustia A (2016) Outcome of zirconia partial fixed dental prostheses made by predoctoral dental students: a clinical retrospective study after 3 to 7 years of clinical service. J Prosthet Dent 116:40-46. https://doi.org/10.1016/j. prosdent.2015.10.026

46. Naenni N, Bindl A, Sax C, Hämmerle C, Sailer I (2015) A randomized controlled clinical trial of 3-unit posterior zirconiaceramic fixed dental prostheses (FDP) with layered or pressed veneering ceramics: 3-year results. J Dent 43:1365-1370. https:// doi.org/10.1016/j.jdent.2015.07.013

47. Sorrentino R, De Simone G, Tetè S, Russo S, Zarone F (2012) Five-year prospective clinical study of posterior three-unit zirconia-based fixed dental prostheses. Clin Oral Investig 16:977-985. https://doi.org/10.1007/s00784-011-0575-2

48. Sailer I, Balmer M, Hüsler J, Hämmerle CHF, Känel S, Thoma DS (2018) 10-year randomized trial (RCT) of zirconia-ceramic and metal-ceramic fixed dental prostheses. J Dent 76:32-39. https:// doi.org/10.1016/j.jdent.2018.05.015
49. Le M, Papia E, Larsson C (2015) The clinical success of toothand implant-supported zirconia-based fixed dental prostheses. A systematic review J Oral Rehabil 42:467-480. https://doi.org/10. 1111/joor. 12272

50. Molin MK, Karlsson SL (2008) Five-year clinical prospective evaluation of zirconia-based Denzir 3-unit FPDs. Int J Prosthodont 21:223-227

51. Rayyan MR (2019) Marginal adaptation of monolithic hightranslucency versus porcelain-veneered zirconia crowns. Int J Prosthodont 32:364-366

52. Morsy N, Kateb M, Azer A, Fathalla S (2021) Fit of monolithic multilayer zirconia fixed partial dentures fabricated by conventional versus digital impression: a clinical and laboratory investigations. Clin Oral Investig. https://doi.org/10.1007/ s00784-021-03845-4

53. Derksen W, Tahmaseb A, Wismeijer D (2021) A Randomized clinical trial comparing the clinical fit of CAD/CAM monolithic zirconia fixed dental prostheses (FDP) on ti-base abutments based on digital or conventional impression techniques One year followup. Int J Prosthodont. https://doi.org/10.11607/ijp.7074

54. Joda T, Zarone F, Ferrari M (2017) The complete digital workflow in fixed prosthodontics: a systematic review. BMC Oral Health 17:124. https://doi.org/10.1186/s12903-017-0415-0

Publisher's note Springer Nature remains neutral with regard to jurisdictional claims in published maps and institutional affiliations. 